\title{
Fábricas selvagens: transformações do trabalho no Polo Industrial da Zona Franca de Manaus
}

\section{The wild factories: transformations of work in the Industrial Pole of the Manaus Free Trade Zone}

Cleiton Ferreira Maciel Brito - Doutor em Sociologia pela Universidade Federal de São Carlos (UFSCar)/professor na Universidade Federal da Grande Dourados (UFGD). E-mail: cleiton.keto@hotmail.com

Jeanne Mariel Brito de Moura Maciel - Doutora em Sociologia pela Universidade Federal de São Carlos (UFSCar)/professora na Universidade Federal da Grande Dourados (UFGD). E-mail: jeannemoura@ufgd.edu.br

\begin{abstract}
Resumo
O objetivo deste artigo é deslindar as principais transformações do trabalho ocorridas no espaço produtivo da Zona Franca de Manaus. Com tal propósito, é feita uma recuperação histórica e teórica das pesquisas realizadas no Polo Industrial de Manaus (PIM) no sentido de apontar, primeiro, as características do trabalho desde o início da década de 1970 até a primeira década do século XX. Segundo, busca-se indicar as respostas conceituais elaboradas pelos pesquisadores para a compreensão de mudanças e continuidades no mundo do trabalho de Manaus. Terceiro, dentro de um contexto de metamorfoses da economia mundial, dos dilemas políticos nacionais e da disputa feita pela classe trabalhadora local, o artigo delineia os padrões organizacionais oriundos de quatro décadas do PIM, e aborda o tipo de trabalho visualizado nas pesquisas mais recentes. Ademais, a chegada de novos atores produtivos no início do milênio, como os chineses, levanta questões teóricas novas, além de abrigar um mundo do trabalho fértil para a exploração sociológica. Uma agenda de pesquisas envolvendo essa temática compõe a parte final do artigo.
\end{abstract}

\section{Palavras-chave}

Trabalho. Polo Industrial de Manaus. Organização da Produção. Globalização.

\begin{abstract}
The objective of this article is to identify the main transformations of the work that took place in the productive space of the Manaus Free Trade Zone. With this purpose, it is made a historical and theoretical recovery of the researches carried out in the Industrial Pole of Manaus (PIM) in order to point out, first, the characteristics of the work from the beginning of the 1970s until the first decade of the 20th century. Second, we seek to indicate the conceptual responses elaborated by the researchers for the understanding of changes and continuities in the world of work in Manaus. Third, within a context of metamorphoses of the world economy, national political dilemmas and the dispute of the local working class, the article outlines the organizational patterns of the four decades of the PIM and addresses the type of work seen in recent research. In addition, the arrival of new productive actors at the beginning of the millennium, like the Chinese, raises new theoretical questions, besides sheltering a world of the fertile work for the sociological exploration. A research agenda involving this theme composes the final part of the article.
\end{abstract}

\section{Keywords}

Work. Industrial Pole of Manaus. Organization of Production. Globalization. 


\section{INTRODUÇÃO}

O Polo Industrial da Zona Franca de Manaus (PIM) fechou o ano de $2016^{1}$ com quase 500 fábricas instaladas, que geraram cerca de 80 mil empregos diretos. $\mathrm{O}$ faturamento foi da ordem de $\mathrm{R} \$ 70$ bilhões, oriundos da participação dos diversos setores de atividades ${ }^{2}$ do PIM: Eletroeletrônico ${ }^{3}(45,33 \%)$, Duas rodas (14,49\%), Químico (15,24\%), Termoplástico (5,86\%), Metalúrgico (5,59\%) e outros (12,96\%) (SUFRAMA, 2017).

Dentro desse cenário da produção industrial amazonense, a indústria de produtos eletroeletrônicos desponta como o principal segmento produtivo da Zona Franca de Manaus. Este subsetor empregou em 2016 cerca de 30 mil trabalhadores nas 120 empresas, dentre as quais se destacam: TPV, Sony, SempToshiba, Philco, Panasonic, Flextronics, Positivo, Samsung, LG, Pioneer, Siemens, Fuji, Foxconn Moebg, Envision e Lenovo (SUFRAMA, 2017).

O segundo maior subsetor é o de duas rodas, empregando em 2016 cerca de 13 mil trabalhadores distribuídos entre 43 empresas, dentre as quais se destacam: Caloi; CR Zongshen; Prince Bike; Kawasaki; J Toledo da Amazônia; Bramont; Dafra; Moto Traxx; Garinni; Haobao; Harley-Davidson; MTD da Amazônia; Yamaha; e Moto Honda (SUFRAMA, 2017).

A instalação dessas empresas em Manaus dá-se em razão desta cidade possuir um modelo de desenvolvimento baseado na atração de investimentos externos via concessão de incentivos fiscais ${ }^{4}$, que compensam a localização geográfica da cidade e sua infraestrutura logística, e faz com que boa parte da produção de produtos eletroeletrônicos e de duas rodas do Brasil se concentre em Manaus. Também se deve ao fato de Manaus possuir reserva de mão de obra barata e qualificada para o tipo de atividade desenvolvida nas indústrias ${ }^{5}$.

\footnotetext{
Dados parciais.

2 O Polo Industrial de Manaus é composto pelos subsetores: eletroeletrônico (incluindo bens de informática), relojoeiro, duas rodas, termoplástico, bebidas, metalúrgico, mecânico, madeireiro, papel e papelão, químico, vestuário e calçados, alimentício, gráfico, ótico, brinquedos, naval e isqueiros--canetas-barbeadores.

3 Inclusive bens de informática.

4 Entre os incentivos fiscais concedidos, se destacam: redução de até $88 \%$ do Imposto de Importação (II) sobre os insumos destinados à industrialização; isenção do Imposto sobre Produtos Industrializados (IPI); redução de 75\% do Imposto de Renda de Pessoa Jurídica, inclusive adicionais de empreendimentos classificados como prioritários para o desenvolvimento regional; e isenção da contribuição para o PIS/PASEP e da COFINS nas operações internas na Zona Franca de Manaus.

5 A ideia de "qualificação" precisa estar relacionada à diversidade de trabalho que existe no PIM, cujo termo "montagem" não ajuda a entender. Nem todo processo de montagem é igual no PIM, e isso implica em diferentes "qualificações". Há processos mais complexos, outros mais
} 
Como um dos lugares onde se realizam a produção e a reprodução da economia globalizada, o Polo Industrial da Zona Franca de Manaus há muito vem sendo palco de intensas mudanças na sua base produtiva e na forma como se dá a relação entre empresas e trabalhadores.

As empresas lá instaladas, por um lado, passaram a estabelecer nas últimas décadas um conjunto de estratégias de gestão do trabalho e de padrão de produção que, em grande medida, caminharam lado a lado das transformações ocorridas no âmbito organizacional em espectro global e nacional.

Já os trabalhadores - em um ambiente com ampla reserva de mão de obra barata à disposição das corporações transnacionais - qual um equilibrista ${ }^{6}$, vêm se movimentando em sentidos diversos na tentativa de compreender, resistir, propor mudanças e acordos diante de um mundo produtivo marcado pela robotização, flexibilização das relações de trabalho, alteração nas formas de gestão e na política de recursos humanos, nas exigências de qualificação/ treinamento e na forma de organização coletiva.

Deslindar o fio histórico dessas mudanças traz luz à compreensão de como elas se encontram hoje, e mais: por concentrar um conjunto de conglomerados das mais diversas regiões do globo, bem como por ser espaço de "encontro" entre região, nação e mundo, o resgate histórico do trabalho no PIM possibilita visualizar o "vai e vem", os deslocamentos, a mobilidade, a expansão ou retração da economia globalizada, suas artimanhas gerenciais e o seu desenvolvimento tecnológico.

Quer dizer, é um espaço privilegiado de análise não somente da economia local, mas do próprio funcionamento da economia global em suas engrenagens fundamentais, qual seja, a relação capital-trabalho, o que em termos de padrão de produção e gestão da mão de obra tem apresentado características diversas no plano local, mas que estão intimamente relacionadas às alterações da empresa mundializada e ao modo como o trabalho e o poder econômico estão divididos internacionalmente.

Tentando mapear essas características, o objetivo deste texto é traçar as principais transformações ocorridas nos processos produtivos do Polo Industrial

simples. Montar pistões de moto, por exemplo, exige conhecimento mínimo de mecânica, o que também é verificado na montagem de ar-condicionado. Montar peças de placas de circuito impresso requer algum conhecimento básico operacional. Montagem de televisores é o processo mais simplificado, necessitando-se de uma qualificação mais "física".

6 Analogia utilizada por Castro (1995) para se referir à situação dos trabalhadores em meio aos processos de inovação tecnológica da indústria automobilística brasileira nos anos de 1990. 
da Zona Franca de Manaus. Além disso, a recuperação histórica tem o fito de esboçar o terreno teórico e histórico para investigações que acompanhem as recentes mudanças que podem estar impactando a região.

É o caso da expansão chinesa e a instalação de suas fábricas globais, que desembarcaram no PIM neste início de milênio. Essas fábricas chinesas têm um histórico internacional de metamorfoses socioeconômicas nos países onde se instalam. Daí o contraste com o passado e o presente produtivo do PIM ser relevante para saber o que os chineses, por exemplo, trazem de novidade no solo nacional.

Buscando destacar esse fio histórico, pensamos que é profícua sua explanação a partir de três recortes temporais que, em grande medida, mostram um certo padrão do tipo de tecnologia, dos processos e das técnicas de gestão utilizados em Manaus, com destaque aos subsetores de eletroeletrônicos e de duas rodas.

\section{O TRABALHO NAS DÉCADAS DE 1970 E 1980}

O primeiro momento inicia na década de 1970 e se estende até final da década de 1980. Esse período foi marcado pela chegada e instalação de grandes empresas produtoras de bens finais, como Semp Toshiba, Moto Honda, Philips, Sharp, Yamaha e Evadin, com produção totalmente voltada para o mercado interno brasileiro.

A julgar pela origem desses primeiros investimentos no PIM, evidencia-se que o deslocamento dessas empresas até Manaus consubstanciava a forma como o capital internacional estava organizado naquele período, tendo o Japão como um grande protagonista não somente na produção de produtos acabados, mas também no fornecimento de tecnologias para outras fábricas. Havia também empresas de capital italiano, americano, alemão, bem como nacional associado ao internacional. Entretanto, a prevalência era do capital japonês, que regionalizava seus processos produtivos globais no espaço produtivo da Zona Franca de Manaus (SERÁFICO, 2011, p. 114).

Sobre esta primeira configuração produtiva da Zona Franca de Manaus, assim pontuam Anciães (1996, p. 46): 
[...] grande parte dos benefícios da Zona Franca de Manaus é usufruída pelo capital internacional - sobretudo o japonês - que instalou montadoras em Manaus ou que fornece tecnologias e/ou equipamentos para outras montadoras, fato que configura que o controle sobre o processo produtivo e o controle da tecnologia permanecem nos centros de origem do referido capital.

Em sentido analítico semelhante, Melo (2010, p. 76-77) observa que a chegada desse conjunto de empresas em Manaus significou uma metamorfose na forma de acumulação de capital em nível global. E esse deslocamento maciço de um conjunto de indústrias revelava uma forma socialmente construída para o capital se reformular, remodelar sua forma de extração de lucro e de criar uma territorialidade outra com força de trabalho nova e dessarajanda coletivamente. E mais: de saída, em desvantagem em relação à organização empresarial que se alinhavou ao Estado. Engendrava-se, assim, um "desenraizamento" da produção capitalista e um consequente enraizamento em solo amazônico sob o protagonismo de indústrias móveis.

Em Manaus, a chegada dessas empresas instaurou uma nova racionalidade social ligada não mais à temporalidade do caboclo ou do ribeirinho - que, agora, passavam a se incorporar ao chão de fábrica - mas vinculada à racionalidade da era do milagre eletrônico ${ }^{7}$. Em lugar da produção extrativista, surgia um novo tipo de produção para o trabalhador local: o trabalho nas fábricas do Polo Industrial de Manaus.

Este cenário revela - para usar a linguagem local - uma espécie de "travessia" que o ribeirinho teve de fazer. Na outra margem do rio formava-se outro tipo de racionalidade, outro imaginário de homem, "uma nova estética e uma nova psicologia", como diria Harvey (2011, p. 121), que colocava Manaus, mais uma vez, na rota da modernidade capitalista.

Com processos de produção simplificados e baseados quase que exclusivamente na realização de operações rotineiras e repetitivas - como lapidação de cristais, montagem de partes de televisores, fabricação de relógios e de produtos eletroeletrônicos, que requeriam habilidades artesanais e semiartesanais (ARAÚJO, 1985) - pode-se dizer que a Amazônia, que outrora havia sido palco da experiência da fábrica de Ford, agora experienciava, com as fábricas do PIM $^{8}$, o "taylorismo amazônico".

Termo cunhado por Araújo (1985).

8 Nessas fábricas do PIM, a política de escolaridade mínima requerida para o ingresso foi estabelecida no "primeiro grau" completo ou, pelo menos, estar cursando o último ano deste grau. Em finais dos anos 1980, a "linha" de corte passou a exigir que o trabalhador estivesse cursando o segundo grau (SPINDEL, 1987). 
Sob estes termos, os anos 1970 e 1980 do Polo Industrial de Manaus não vão requerer "qualificação" da mão de obra local, sendo fundamental apenas que fosse abundante e dócil, com idade entre 15 e 25 anos e com renda bruta de até dois salários mínimos. Sobre essa questão da qualificação do trabalhador nos primeiros anos do Polo Industrial de Manaus, assim a aborda Spindel (1987, p. 3):

A bem da verdade, a mão de obra, no que se refere a volume e preços, se configurou sobretudo nos primeiros anos da implantação do Distrito como um dos maiores problemas enfrentados pelos empresários. Os trabalhadores mais qualificados, técnico e de supervisão, bem como toda a gerência, foi arregimentada no sul do país, vinda sobretudo de São Paulo. Para atrair essa mão de obra era necessário oferecer níveis salariais bem mais elevados do que aqueles possíveis de serem obtidos no mercado de trabalho de origem e/ou incentivos que representassem vantagens diferenciais atraentes.

No tocante à qualificação dos trabalhadores do chão de fábrica no período, Valle (2007, p. 138) observa que "em todos os setores, a mão de obra não qualificada supera $50 \%$ do total, realizando tarefas repetitivas que não requerem conhecimento técnico, qualificação ou especialização e experiência anterior."

Afora isso, sobressaía-se já naquele período um traço característico do trabalho no PIM até hoje: o trabalho feminino no setor de manufatura eletrônica, seja porque a mão de obra era tida como a mais adequada ao tipo de trabalho desenvolvido nas fábricas de Manaus, seja porque os salários pagos às mulheres eram inferiores aos dos homens (SCHERER, 2005, p. 67).

Sobre esse aspecto, Salazar (1992, p. 309) destaca um depoimento operário que expressa as "qualidades" peculiares das mulheres para o trabalho industrial:

Mais de 95\% das montadoras do distrito industrial são mulheres. Isso se justifica porque é uma mão de obra mais barata, tem mais responsabildiade que o homem, ela geralmente não bebe, ela dá conta melhor desses trabalhos minuciosos, de montagem de pequenas peças, tem aquele jeitinho de mulher, ela dá conta com mais facilidade que o homem, ela é geralmente mais temerosa às leis, às greves, menos infiltrada nos movimentos sindicais, pode ser mais explorada que o homem, então seria o operário ideal; o que a gente nota é que a partir daí o distrito industrial começou a requisitar mulheres com mais frequência, devido a

\footnotetext{
9 Vale ressaltar que, não obstante a qualificação para o trabalho ser mínima, a escolaridade das operárias da indústria eletroeletrônica não somente era superior ao nível médio da região como também se situava acima dos patamares nacionais nas indústrias do ramo (SPINDEL, 1987, p. 9).
} 
esses requisitos, levando em conta só uma coisa: mulher com filhos ${ }^{10}$ não, eles não querem, eles mesmos divulgam isso, mulheres solteiras entre 17 e 25 anos, sem experiência anterior. Então, a maioria das mulheres são operadoras, são poucas as que estudam, devido ao horário de trabalho, então quando muito elas terminam o segundo grau.

Desse tempo, um outro aspecto importante a ser evidenciado são as técnicas de gestão da mão de obra e a política de recursos humanos, que vão ser caracterizadas pelo grande número de níveis hierárquicos, por grandes estruturas burocráticas, por um processo decisório de "cima para baixo", pela ausência de política de treinamento, por organização em departamentos rígidos e pelo uso intensivo de mão de obra com estrutura de cargos baseada em postos de trabalho (OLIVEIRA, 2007, p. 59). Isso significou que o processo de produção estruturava um tipo de trabalhador sem nenhuma noção do processo produtivo como um todo, transformando o seu trabalho em uma constante repetição de atividade.

Como padrão de produção, observa-se nos anos de 1970 até finais da década de 1980 a estruturação de certa cadeia produtiva, principalmente no setor de eletroeletrônico. Esse processo objetivava-se no fato de as grandes empresas produzirem em Manaus os próprios insumos a serem utilizados na linha de montagem. No caso de televisores, por exemplo, havia departamentos da fábrica onde se montavam, manualmente, placas, transistores, alto-falantes, tubos de imagem etc.

Também havia um sistema de produção online, quer dizer, sobre a linha, o que, efetivamente, significava que testes nos produtos, consertos e reparos eram feitos, em sua maioria, fora da linha de produção, tendo um grupo de pessoas que, literalmente, desmontavam os produtos e depois remontavam para, então, colocá-los na linha de produção novamente. Eram os chamados cabineiros ou convergistas, funções operacionais que remontam a esses primeiros anos da produção de eletroeletrônicos no Polo Industrial de Manaus.

Pode-se dizer, à primeira vista, que isso resultava da indisponibilidade de tecnologia mais avançada no período, o que fazia com que se requeresse trabalho humano direto. No entanto, o fato é que a modernização do processo

10 Analisando este aspecto no Polo Industrial de Manaus dos anos 1980, Spindel (1987) apontou como os filhos das operárias eram o motivo mais frequente de falta no trabalho, mas que isto significava pouco em termos de custo de produção, uma vez que dois dias de faturamento cobriam toda a folha de salário do mês. Apesar disso, as empresas passaram a distribuir pílulas anticoncepcionais entre as trabalhadoras ou, em caso de esterilização ("amarrar as trompas"), emprestar-lhes dinheiro para a realização do procedimento. 
de produção representava custos que não interessavam às empresas em face da reserva de mercado que lhes era garantida. Dito de outro modo, o uso do capital variável era mais lucrativo às empresas do que investimentos em capital constante (ARAÚJO, 1985, p. 256).

Vale destacar, por fim, a organização dos trabalhadores como elemento fundamental do trabalho desse período. Se na década de 1970 o movimento sindical ainda era incipiente, sendo o controle sindical quase inexistente e muito atrelado ao patronato, a década de 1980 - em face do cenário de redemocratização do país, das greves do ABC, que "inspiravam” outros coletivos de trabalhadores, e do nascente processo de automação - vai trazer o sindicato à organização e à atuação, instaurando-se muitas greves e conflitos nas fábricas do Polo Industrial de Manaus.

Esse contexto compõe um universo de reivindicações e conquistas da classe trabalhadora, dentre as quais pode-se destacar:

a redução da jornada de trabalho, reposição salarial, abonos salariais, melhorias nas condições de trabalho, medidas de prevenção contra acidentes, assistência médica e ambulatorial, prolongamento da licençamaternidade, dentre outras (REIS FILHO, 2013, p. 20).

\section{O TRABALHO NA DÉCADA DE 1990}

Este cenário construído entre os anos de 1970 até finais de 1980 vai sofrer uma grande transformação a partir do início da década de 1990. Isso resulta, como salienta Valle (2007, p. 151), do fato de as empresas da Zona Franca de Manaus terem sido fortemente afetadas pelas mudanças econômicas e de política tributária promovidas pelo governo Collor, que reduziu as alíquotas de importação em todo o território nacional. Tal situação ainda foi agravada pela estagnação econômica que se abateu sobre o Brasil a partir de 1991.

Se antes havia uma barreira à importação de bens eletrônicos de consumo e de outros produtos, sua retirada significou a perda de um dos pilares que sustentavam, também, um tipo de organização produtiva em vigor em Manaus.

No tocante ao novo tipo de empresa e ao seu padrão tecnológico que emerge desse cenário, destacam-se o início do uso da automação microeletrônica, a chegada de máquinas axiadoras e a redução de estoques nas empresas. Iniciase um intenso processo de racionalizaçao da produção vinculada à máxima de 
"redução de custo", reduzindo o contingente de trabalhadores empregados no Polo Industrial de Manaus.

Na década de 1980, as linhas de produção não eram automatizadas, mas esse novo momento trouxe a inserção de testes automáticos de componentes em placas de circuito impresso, tornando-se um "padrão" no PIM (SILVA, 2010). Trouxe, também, a expansão da microeletrônica, com as máquinas axiais, sequenciadoras e SMDs (Surface Mounted Device) que reduziram os tempos de produção e elevaram a precisão da montagem de componentes sobre a placa de circuito impresso.

Analisando as consequências desse processo de inovação tecnológica no Polo Industrial de Manaus, Valle (2007, p. 170-171) destaca que essa automatização de certas etapas do processo de produção:

aumenta a intensidade de capital na indústria de eletroeletrônicos de consumo. Essa automatização possibilita maiores volumes de produção [...]. Além da intensificação no grau de automação na montagem de placas de circuito impresso, as empresas introduziram, nas linhas de produção, equipamentos computadorizados de teste, e algumas renovaram as linhas de produção através de equipamentos de gerações tecnológicas mais recentes.

A reorganização do processo no PIM também estabeleceu um sistema de flexibilização da produção e da mão de obra que, por seu turno, incluiu como parte do leque de inovações organizacionais a introdução de células de manufatura, sobretudo nos setores de fabricação de áudio e vídeo. Isso provocou um redimensionamento da produção via redução da divisão e fragmentação das tarefas, eliminação da supervisão direta, o controle informal do trabalho e introdução da ideia de "cliente interno".

Pari passu a este processo, tem início uma corrida das empresas em busca de certificação internacional de qualidade. Isso estava associado ao fato de que em 1993, por meio de um decreto presidencial 783, de 25 de março de 1993, passou-se a exigir que as empresas implantassem normas técnicas de qualidade, conforme padrões de entidades credenciadas pelo Instituto Nacional de Metrologia, Normalização e Qualidade Industrial (INMETRO).

Essas transformações, conjugadas, engendraram novas formas de contratação da mão de obra que consolidou como política de contratação o nível de Ensino Médio completo como escolaridade mínima. O discurso da época era que um trabalhador com mais escolaridade seria mais suscetível a aprender e a 
adotar as novas normas de fabricação, os novos procedimentos de inspeção e a nova "cultura da qualidade" que estava nascendo. A este respeito, Oliveira (2007, p. 62) aponta que, ao contrário do que havia nas décadas de 1970 e 1980,

quando não eram exigidos da grande maioria dos trabalhadores conhecimento mínimo adequado e escolaridade mínima para ingresso nos trabalho, hoje as empresas estão a exigir nível médio de instrução escolar e conhecimentos complementares para ingresso na indústria eletroeletrônica. Evidentemente, esse padrão de gestão e seleção de mão de obra deve-se também à existência de um grande contingente de trabalhadores desempregados e escolarizados.

Nas avaliações das gerências, um trabalhador com maior nível de escolaridade era mais propenso a dar ideias, contribuir na melhoria dos processos de trabalho. $\mathrm{Na}$ verdade, o que estava ocorrendo e que estava por detrás desse "diagnóstico gerencial" era o nascimento de uma "nova cultura do trabalho", na qual os aspectos subjetivos do trabalhador também passaram a ser racionalizados, ou seja, movimentados como elemento que contribuía para o aumento da produtividade e geração de lucro para a empresa (SILVA, 2010).

Aflorou-se, assim, a ideia de "cooperação" e "participação" do trabalhador na atividade produtiva, tornando essa uma das características fundamentais do trabalho no Polo Industrial de Manaus na década de 1990. Sintomaticamente, além desses critérios de contratação de mão de obra mencionados, passou-se a exigir um trabalhador com "carteira profissional limpa" e "portador de necessidades comportamentais como responsabilidade, iniciativa, atenção, facilidade de relacionamento, destreza, flexibilidade, caráter, boa índole, personalidade, vontade de trabalhar e o "engajamento no jeito de ser da empresa"' (VALLE, 2007, p. 184-185).

Para a concretização e emulação desses objetivos, lançou-se mão da introdução de métodos organizacionais oriundos do chamado "modelo japonês", como os Grupos de Melhorias, o Kaisen, o Kaban, os 5S e as tentativas de implantação do sistema just in time. Dentre estes, os grupos de melhoria foram os que mais se disseminaram pelo Polo Industrial de Manaus ${ }^{11}$, passando a ser um instrumento gerencial considerado best way para o "envolvimento" dos

11 Em pesquisa de campo realizada no munícipio de Iranduba, Região Metropolitana de Manaus, Maciel (2013) observa que as fábricas ceramistas daquela região se encontravam em intenso processo de adoção de técnicas gerenciais "modernas", como os Círculos de Controle de Qualidade. Isso mostra como as inovações organizacionais não ficaram restritas apenas ao Polo Industrial de Manaus, mas avançaram inclusive sobre os setores "tradicionais" da indústria amazonense. 
trabalhadores dos subsetores de duas rodas e de eletroeletrônicos. Um dos principais aspectos dessa "cultura do envolvimento", a "pedra de toque" da ação empresarial, foi a figura do "colaborador", como atestam os trabalhos de Oliveira (2007), Valle (2007), Scherer (2005), Silva (2010), Moraes (2010) e Andrade (2014).

$\mathrm{Na}$ avaliação de Valle (2007, p. 201), a implantação desses grupos de melhoria e de controle de qualidade significou:

uma ampliação do controle gerencial sobre o processo produtivo que se utiliza, para isso, da inteligência e conhecimentos técnicos dos próprios trabalhadores. Não se trata de uma participação efetiva posto que não se compartilham decisões, mas de um processo de integração e cooptação a um programa de envolvimento formulado pela gerência e cuja execução depende da colaboração dos trabalhadores.

Todo esse processo teve profundo impacto nas formas de vínculos trabalhistas, afugentando o trabalhador do sindicato, como observa Valle (2007, p. 159-160):

Vínculos frágeis caracterizavam a situação dos representantes dos trabalhadores nos planos interno e externo [...]. O discurso articulado de porta de fábrica já não tem o mesmo apelo, a aposta no confronto não mobiliza, como no passado recente, os trabalhadores industriais.

Esse conjunto de mudanças no mundo do trabalho apontava para um Polo Industrial de Manaus diferente daquele delineado nos anos de criação da Zona Franca de Manaus. Em lugar da linha de montagem intensiva em trabalho manual, emergiu a automação como instrumento fundamental de aumento da produção e da intensificação do trabalho, não obstante a permanência da inserção manual, principalmente na produção de televisores e aparelhos celulares. Surgiu, outrossim, o trabalho polivalente e multifuncional que teve como concepção a realização de várias funções e não mais um trabalho baseado em postos. Engendrou-se, ainda, uma linha de montagem flexível e, ao seu lado, o trabalho em células de produção.

$\mathrm{Na}$ avaliação de Valle (2007), as formas de gestão e as inovações tecnológicas implementadas nas fábricas da Zona Franca de Manaus mostravam um padrão fabril diferente do padrão taylorista, mas que se distanciava da versão original da produção flexível, levando a autora a denominar esse processo como um neotaylorismo, uma amálgama de mudanças e permanências.

Defendendo um sentido oposto ao discurso de emergência de um padrão produtivo totalmente novo, Oliveira (2007) pontua que a lógica que passou a 
predominar nas indústrias da Zona Franca de Manaus "parece ser a de transformar tudo o que cerca o trabalho, desde a organização espacial, passando por cursos com conteúdos de filosofia, reuniões de CCQs etc., sem que o próprio trabalho seja modificado significativamente" (OLIVEIRA, 2007, p. 209).

\section{O TRABALHO NOS ANOS 2000}

Nos anos 2000 em diante, apesar da maior parte das investigações não terem como foco primordial o processo e a organização do trabalho, pesquisas realizadas neste período vêm apontando para um aprofundamento do quadro delineado anteriormente, com destaque à divisão sexual do trabalho, sobretudo nas áreas automatizadas, acompanhado da redução de níveis hierárquicos, novas ferramentas e critérios de contratação, consolidação de políticas de envolvimento operário e concessão de premiação e reconhecimento aos trabalhadores como forma de afastá-los dos sindicatos e aumentar a produtividade.

No intuito de reduzir custos e melhorar os processos produtivos, tem ocorrido a dinamização da racionalização iniciada nos anos 1990, como a introdução de tecnologias e de automação de várias etapas da produção. Na Moto Honda, por exemplo, o total da produção, que era de 3 milhões de unidades até ano 2000, saltou para 13 milhões em 2009, resultado muito influenciado pela automatização, principalmente nos processos de soldagem e de produção de chassi, como aponta Araújo Filho (2005), bem como Melo (2010).

Associado a isto, ocorre uma mudança no perfil do trabalhador contratado que, agora, ao invés de se restringir ao saber técnico e à qualificação profissional, passa-se a exigir certas competências, como comprometimento, produtividade e pouco absenteísmo. Como forma de incentivo aos possuidores dessas competências, as empresas têm oferecido acesso a cursos de qualificação e ajuda de custo para a realização de faculdade ou curso de línguas (SAMPAIO, 2012). A ideia de "competências" surge, assim, como elemento central no emprego e a qualificação, mas, contraditoriamente, não tem sido garantidora de estabilidade para os trabalhadores (PEREIRA, 2013).

Do ponto de vista da estrutura das empresas, irrompeu-se um profundo processo de redução de níveis hierárquicos nas grandes corporações transnacionais instaladas no PIM. Baseando-se no princípio da fábrica enxuta, instituído em Manaus, como vimos, na década de 1990, muitas empresas, nos anos 2000, intensificaram a racionalização do uso da força de trabalho, ao mesmo tempo 
em que se vislumbraram melhorias na fluidez da informação, "com a eliminação de parte dos cargos de gerência, supervisão, reservas, chefias intermediárias etc." (OLIVEIRA, 2006, p. 697).

Outra face desse controle do trabalho no Polo Industrial de Manaus vem sendo moldada mediante uma política de gestão da mão de obra baseada na ideia de "comprometimento com a qualidade", sendo isso mais latente nas empresas de capital japonês. Moraes (2010, p. 186), por exemplo, analisando a relação entre "prazer e sofrimento" nas fábricas nipônicas, destaca que estas empresas têm tido no "paradigma da qualidade total" a principal referência.

Para a implementação da "cultura da qualidade" nessas fábricas, todos os espaços da produção passaram a ter cartazes indicando os objetivos da empresa e o que "é" qualidade. Também foram estabelecidas reuniões semanais onde os gerentes explicam "onde está o defeito e enfatizam a cultura da excelência". "A primazia da qualidade é mais evidente na área de inserção automática que nas outras áreas das fábricas. A velocidade das máquinas potencializa a extensão de um erro, particularmente na seção de $S M D$ (?), onde as máquinas são muito rápidas" (MORAES, 2010, p. 188).

Além disso, estas empresas têm lançado mão da propaganda de si mesmas como forma de conseguir o "comprometimento do trabalhador". Para isso, faz-se uso da exaltação da ideologia da empresa (lema anual da organização) e engendram-se políticas de engajamento do trabalhador por meio de elogios, premiações e murais, a partir das quais se mostram os "melhores colaboradores" do processo produtivo, criando "distinções simbólicas" entre eles.

O significado disso, segundo Moraes (2010), é o recurso à subjetividade do trabalhador para organizar a gestão do trabalho. E um desses "recursos do método do capital" - para usar uma expressão de Oliveira (2004, p. 11) - é tratar o trabalhador "como se fosse da família". Exemplo de como essa estratégia gerencial tem sido utilizada pelas empresas japonesas é a implementação de "agrados" ao funcionário dentro e fora da fábrica, que visam moldar a subjetividade do trabalho às artimanhas empresariais.

Processos semelhantes a estes são observados por Andrade e Valle (2011) e Andrade (2014), quando de suas análises da relação entre empresa/ trabalhador no subsetor de duas rodas do Polo Industrial da Zona Franca de Manaus. O autor pontua que a fábrica japonesa do PIM estava desenvolvendo uma artimanha gerencial baseada em uma política de treinamento visando inculcar o "modelo japonês" como filosofia de trabalho e de vida para os 
seus "colaboradores". Perseguindo isso, instituiu-se um intenso processo de "produção de colaboradores".

Emumadessasempresasdosubsetordeduasrodas,porexemplo,construíram-se espaços de treinamento para a realização de cursos, como 5S, Curso J, Kaizen, Kanban, Brigada de incêndio e Metrologia básica. Também foram criados centros médicos, odontológicos e de farmácia na estrutura na planta fabril da própria empresa. Em certo aspecto, tal artimanha visa criar um ambiente social na empresa propício para que o trabalhador se "sinta em casa", a despeito de trabalhar para a empresa.

Mas o "carro-chefe" da empresa é o ensino da Filosofia Honda aos “colaboradores" tão logo o indivíduo adentre os portões da fábrica. Tal processo consiste em envolver o trabalhador na organização da fábrica, tornando-o um "colaborador" e, para isso, são distribuídos livros de bolso contendo os "ensinamentos" dos fundadores da Honda e é oferecido o curso "Filosofia Honda", ministrado no Centro de Treinamento pelos instrutores da própria empresa.

Além disso, lança-se mão dos Círculos de Controle de Qualidade como forma de se mostrar os princípios de gestão da empresa, dentre os quais se destacam: respeito pelos clientes, fornecedores, colaboradores, familiares e vendedores; iniciativa para colaborar e crescer na empresa; confiança entre os "colaboradores" e entre gerentes; e "Alegria de Comprar, Alegria de Vender e Alegria de Criar" (ANDRADE; VALLE, 2011).

A despeito de a empresa apontar a "colaboração" como uma ferramenta de inovação do trabalho que "valoriza" o talento, a criatividade e proatividade do trabalhador e que contribui para um aperfeiçoamento das relações de trabalho e da produção como um todo, a pesquisa de Andrade (2014) revela as contradições envolvendo um processo que, travestido da noção de "colaboração", encobre diferentes formas de dominação. Isso porque ser "colaborador" não é uma escolha, mas uma obrigação, tendo em vista que no contrato de trabalho as empresas japonesas expressam que o contratado deve se comprometer com as atividades desenvolvidas na empresa.

Além disso, Andrade (2014) mostra que há todo um esforço da gerência de agir com carisma a fim de cativar os hábeis trabalhadores à sua causa, intentando, com isso, afastar a possibilidade de outras formas de coletivização que não seja aquela voltada para o lucro da empresa (ANDRADE, 2014). Inobstante isso, as empresas japonesas - principalmente as do subsetor de suas rodas - têm 
conseguido manter baixos índices de rotatividade entre os trabalhadores, muitos deles possuindo mais de 30 anos de trabalho na empresa.

Observando este fenômeno, Andrade (2014, p. 129) também questiona a baixa rotatividade e a explica nestes termos:

o trabalhador pode muito bem se utilizar de sua condição de voluntário ao trabalho e à escolha da empresa para trabalhar e optar por investir seus esforços em outra fábrica. Mas por que não o faz? Por razões diversas. Sempre é um risco perder um emprego. Muitos têm medo do novo. Uma grande parcela dos trabalhadores não tem qualificação suficiente que lhe deixe seguro de arriscar uma mudança de emprego. Então, o que acontece é uma espécie de consentimento entre os trabalhadores e a empresa. Os "colaboradores" agem e atuam não por alienação, mas por necessidade. É uma ação racional instrumental.

Outra característica do trabalho no PIM são as redes de fornecedores e sua interação com a empresa matriz, conformando uma "horizontalização" das relações entre empresas na Zona Franca de Manaus, tendência já observada por Valle (2007) e Oliveira (2007). Analisando esse processo em uma empresa japonesa, Melo (2010) destaca que, desde os anos 1990, a criação de cadeias produtivas tem sido a tônica das relações empresariais nesse setor fabril no Polo Industrial de Manaus sob a égide do modelo just in time/Kanban no regime de produção flexivel e que, a despeito do discurso de uma produção mais enxuta e com menos gastos para os participantes da rede, a empresa matriz é quem tem sido a maior beneficiada dessa prática.

Ao trabalhar em cima desse modelo "enxuto", as empresas transferem para os seus fornecedores os gastos com o estoque, revelando, dessa forma, que não há parceria, mas certa subordinação e dependência (MELO, 2010). A exemplificação disso seriam as próprias empresas japonesas do subsetor de duas rodas que, em virtude da necessidade de fazer estoque de três dias para compras nacionais e de 10 dias para as internacionais, transferem essa responsabilidade para as suas fornecedoras locais, repassando-lhes o custo do sistema de horizontalização da produção. Ao lado destes processos, ocorre também um amplo movimento de terceirização protagonizado pelas fábricas instaladas no Polo Industrial de Manaus.

Comparativamente, se nos anos de 1990 a terceirização vinha se dando somente em relação a serviços para além da produção, como refeição, limpeza e segurança (SCHERER, 2005; VALLE, 2007; OLIVEIRA, 2007; SILVA, 2010; MORAES, R., 2010), nos últimos anos isso se expandiu para outros setores das 
fábricas. No caso do subsetor de duas rodas, por exemplo, a terceirização tem sido utilizada no processo de montagem dos produtos, com linhas terceirizadas para outras empresas.

Já no subsetor de eletroeletrônicos, a terceirização vem se espraiando em áreas que não da produção, mas da estrutura organizativa da fábrica, alcançando patamares superiores a 30\% em algumas empresas. Oliveira (2006, p. 697) destaca essa configuração:

A maioria das áreas/departamentos das empresas [...] é composta exclusivamente por mão de obra subcontratada e apresenta redução significativa do número de funcionários. Chama a atenção o fato de algumas áreas, como engenharia industrial, engenharia de processo, planejamento e controle, administração de pessoal, controle de qualidade, materiais, compras, antes muito valorizadas e prestigiadas, funcionarem inteiramente, nos dias atuais, com mão de obra terceirizada.

O objetivo dessa ação empresarial é a redução de custos, mas controlando in loco o processo produtivo. Em termos de relação de trabalho, isso tem criado uma distinção simbólica e prática entre trabalhadores, pois os que trabalham nas terceirizadas, apesar de estarem dentro da própria planta da empresa que terceiriza, não ganham os mesmos benefícios e nem têm os mesmos treinamentos que os "colaboradores". Além disso, têm salários mais baixos quando comparados aos da empresa matriz (OLIVEIRA, 2011).

Isto posto, vale destacar o protagonismo que as empresas japonesas vinham tendo no conjunto macro das transformações do trabalho no PIM, tendo não somente produção majoritária entre as fábricas que produzem o bem final, mas também entre as subsidiárias. Criou-se em Manaus uma espécie de "niponização" da cadeia produtiva, o que é corroborado pelo relacionamento prévio entre essas empresas dentro do próprio Japão, levando à transferência de capital acumulado em relações de negócios deste país para o Brasil, dada a filosofia japonesa de que "se deve produzir no local onde se vive" (MELO, 2010, p. 164).

Segundo Moraes (2011, p. 39-40):

não apenas ocorreram transferências de capital, mas de relações de trabalho, práticas e valores típicos daquele país, reforçando ainda mais a participação da colônia japonesa em território amazônico, que, inclusive, antecede ao advento da Zona Franca, porém outrora concentrada na atividade agrícola. 
No entanto, pouco a pouco, outros atores produtivos desembarcaram na Zona Franca de Manaus e foram conquistando espaços no final dos anos 1990 e começo do atual milênio, notadamente as empresas asiáticas, de origem sulcoreana (LIMA; VALLE, 2013). A exemplo das empresas japonesas, as empresas coreanas que chegaram a Manaus se deslocaram, sobretudo, para o segmento de eletroeletrônico, fabricando componentes de celulares, computadores e televisores, assim como esses próprios bens finais.

A partir de meados dos anos 2000, as empresas chinesas também passam a se direcionar a Manaus. Outrora apenas espaço da globalização, com inúmeras zonas francas em seu território, os chineses, numa corrida econômica sem precedentes, tornam-se um player global e se dirigem para "a zona franca da selva", com uma plataforma industrial mais irradiada que as sul-coreanas, pois se estabeleceram não somente no subsetor de eletroeletrônicos, mas nos principais subsetores do Polo Industrial de Manaus.

Com efeito, os estudos até aqui realizados sobre os trabalhadores e empresas da Zona Franca de Manaus se debruçaram sobre as empresas de origem norte-americana, europeia e asiática. No caso do capital asiático, as pesquisas têm se concentrado, na sua maior parte, nas empresas japonesas, de sorte que entender o que a chegada das empresas chinesas significa em termos de organização do trabalho no "chão" e nos “altos" espaços da fábrica local é ainda algo por descobrir, reclamando por novas investigações.

\section{UMA NOVA AGENDA DE INVESTIGAÇÕES}

Historicamente, observa-se que o trabalho na Zona Franca de Manaus foi alterado significativamente. De um processo com características tayloristas, passou-se a ter como base de organização da produção as influências gerenciais japonesas. Os estudos mais recentes feitos no PIM enveredaram nesse caminho, qual seja, analisar estas transformações, apontando para especificidades organizacionais de origem japonesa e de como estas, em boa medida, espraiaram uma cultura do trabalho pelo PIM, atingindo empresas não orientais, por exemplo. Círculos de Controle de Qualidade, gestão participativa, colaboração e trabalho multifuncional são expressões disso.

Por seu turno, a chegada de outros atores produtivos, como os chineses, coloca a questão de saber o que há de novo e como as concepções organizacionais 
discutidas pelos autores aqui citados estão sendo ou não sendo modificadas face à entrada de um player mundial, que é a China.

Com volumes de investimentos consideráveis e estrategicamente direcionados, os chineses, como indicam Lima e Valle (2013, p. 79), apostam na tentativa de se formarem "pequenas Chinas" em territórios produtivos diversos, imprimindo nestes uma lógica de produção cujos significados e consequências sobre a organização do trabalho, em nível mundial, ainda foram pouco estudados. Em nível local, há, também, uma lacuna a ser preenchida por futuras pesquisas.

Observando o caso dos chineses, por exemplo, é necessário inquirir se as fábricas estão andando na direção contrária aos tipos gerenciais visualizados em pesquisas feitas dantes, para ficar apenas nas investigações sobre o Polo Industrial de Manaus. Depois, precípuo é ver se o padrão de produção e gestão do trabalho têm reverberações na fábrica chinesa. Se sim, de que forma? Se não, por quê?

Ademais, no conjunto dos estudos internacionais sobre o trabalho nas fábricas localizadas na própria China, uma corrente vem mostrando uma diversidade de "regimes de trabalho" e de formas de gestão que não apontam para nenhum "modelo" fabril no território chinês (JIA, 2016; LEE, 1999; 2007; LU, 2016; SMITH; ZHENG, 2016). Contudo, outra corrente, indica a proliferação daquilo que tem sido denominado como "taylorismo sangrento" e “despotismo gerencial” (CHAN; PUN, 2010; CHAN; PUN; SELDEN, 2013; VAN LIEMT, 2016).

Isso coloca a questão de saber se a "fase internacional" das companhias chinesas está sendo operada sob padrões de produção e de gestão de trabalho "difusos" e diversos, como indica a primeira perspectiva teórica, ou se há um "padrão", como aponta a segunda. Diante disso, cabe inquirir o que é difuso e diverso nestas fábricas, bem como o que é "padrão".

Outrossim, pesquisas como a de Andrijasevic e Sacchetto (2016) e de Lee (2009) deslindam processos de precarização protagonizados pelas empresas chinesas no leste europeu e no continente africano. Isso instiga a entender se questões semelhantes estão a ocorrer em Manaus. Se sim, de que forma? E é precarização em relação ao quê?

Além dessas questões investigativas postas acima, outras que sinalizam uma nova agenda de pesquisa sobre o PIM são: como os trabalhadores percebem a gestão chinesa nas fábricas? E o sindicato, qual a sua avaliação? Quais as inovações tecnológicas introduzidas? Em que elas diferem das anteriores? E os processos 
de trabalho, como eles têm sido organizados em face da gestão chinesa? Qual o tipo de trabalhador requerido pelas empresas? Que tipo de qualificação tem sido exigida? Quais formas de controle da mão de obra são utilizadas pelos chineses? Há transferência de tecnologia? E de pessoas? Se sim, como e em quais termos se dá essa mobilidade? Esse conjunto de questões apontaria para um novo padrão de acumulação sob o protagonismo chinês?

Esse leque de questões de pesquisas, aliado à recuperação histórica do trabalho no PIM, pode indicar novos caminhos da organização da produção, novas pautas de lutas dos trabalhadores e novas mobilidades na cidade de Manaus. Daí ser fundamental a movimentação de pesquisas que inquiram os significados sociológicos deste encontro entre atores produtivos emergentes, como os chineses, e esse "espaço da globalização" (LIMA; VALLE, 2013), que é a Zona Franca de Manaus.

\section{REFERÊNCIAS}

ANCIÃES, A. W. F. (Coord.). Avaliação da Zona Franca: subsídios para a formulação de uma política tecnológica. Brasília: CNPq/UECE, 1996.

ANDRADE, A. S. de. Como se produzem “colaboradores"? Entre prática de gestão e intensificação do trabalho no polo duas rodas em Manaus. 2014. Dissertação (Mestrado em Sociologia). Instituto de Ciências Humanas e Letras, Universidade Federal do Amazonas, Manaus, 2014.

ANDRADE, A. S. de; VALLE, M. I. M. Modelo japonês e práticas de gestão na indústria de veículos sobre duas rodas da Zona Franca de Manaus. Novos Cadernos NAEA, Belém, v. 14, n. 2, p. 141-170, dez. 2011.

ANDRIJASEVIC, R.; SACCHETTO, D. Foxxconn Beyond China: capitallabour relations as co-determinants of internacionalization. In: LIU, M.; SMITH, C. (Eds.). China at work: a labour perspective on the transformation of work and employment in China. UK, London: Palgrave Macmillian Education, 2016. p.337-360.

ARAÚJO FILHO, G. de. Cooperação entre empresas no Polo Industrial de Manaus. 2005. Tese (Doutorado em Engenharia de Produção) - Universidade Federal do Rio de Janeiro, Rio de Janeiro, 2005. 
ARAÚJO, N. Y. B. de. O milagre dos manauaras: Zona Franca de Manaus: uma análise do processo de industrialização implantado em Manaus e da universidade como formadora da mão-de-obra especializada. 1985. Dissertação (Mestrado em Educação) - Instituto de Estudos Avançados em Educação, Fundação Getúlio Vargas, Rio de Janeiro, 1985.

CASTRO, N. A. de (Org.). A máquina e o equilibrista. Inovações na indústria automobilística brasileira. São Paulo, Paz e Terra, 1995.

CHAN, J; PUN, N. Suicide as protest for the new generation of Chinese migrant workers: Foxconn, global capital and the state. The Asia-Pacific Journal, Kyoto, v. 8 , n. 37 (2), p. 1-50, 2010.

CHAN, J.; PUN, N.; SELDEN, M. The politics of global production: Apple, Foxconn and China's new working class. New technology, work and employment, Kyoto, v. 11, n. 28 (2), p. 100-115, 2013.

HARVEY, D. Condição pós-moderna: do fordismo à acumulação flexível. São Paulo: Loyola, 2011.

JIA, W. The making of a dualistic labour regime: changing labour process and power relations in a chinese state-owned enterprise under globalization. In: LIU, M.; SMITH, C. (Eds.). China at work: a labour perspective on the transformation of work and employment in China. UK, London: Palgrave Macmillian Education, 2016. p. 76-97

LEE, C. K. From organized dependence to disorganized despotism: changing labour regimes in chinese factories. The China Quartely, Pequim, v. 157, p. 44-71, 1999.

LEE, C. K. Against the law: labour protests in China's rustbelt and sunbelt. Berkley: University of California Press, 2007.

LEE, C. K. Raw Encounters: Chinese Managers, African Workers and the Politics of Casualization in Africa's Chinese Enclaves. The China Quarterly, Pequim, n.199, p. 647-666, set. 2009.

LIMA, J. C.; VALLE, M. I. de M. Espaços da globalização: Manaus e as fábricas na Amazônia. Revista Contemporânea, São Carlos v. 3, n. 1, p. 73-88 jan./jun. 2013. 
LU, M. Control and consent in the process of employee participation in a chinese state-owned enterprise: the case of BZ Iron and Steel Company. In: LIU, M.; SMITH, C. (Eds.). China at work: a labour perspective on the transformation of work and employment in China. UK, London: Palgrave Macmillian Education, 2016. p. 31-55.

MACIEL, C. F. "Homens do barro" e estratégias empresariais: um estudo da relação capital-trabalho no Polo oleiro-cerâmico da Região Metropolitana de Manaus-AM. 2013. 161 f. Dissertação (Mestrado em Sociologia) - Instituto de Ciências Humanas e Letras/ICLH/UFAM. 2013.

MELO, E. L. A formação da rede de produção na indústria sobre veículos de duas rodas do Norte brasileiro. 2010. 171 f. Dissertação (Mestrado em Sociologia) - Universidade Federal do Amazonas, Manaus, 2010.

MORAES, E. de O. Corporação em rede: um estudo sobre a moto Honda da Amazônia. 2011. 92 f. Dissertação (Mestrado em Geografia) - Universidade Federal do Amazonas, Manaus, 2011.

MORAES, R. D. de. Prazer-sofrimento no trabalho com automação: estudo em empresas japonesas no Polo Industrial de Manaus. Manaus: Editora da Universidade Federal do Amazonas, 2010.

OLIVEIRA, F. Um prefácio Dialogal. In: GUIMARÃES, N. A. Caminhos cruzados: estratégias de empresas e trajetórias de trabalhadores. São Paulo: USP, Curso de Pós-Graduação em Sociologia: Editora 34, 2004.

OLIVEIRA, S. S. B. de. O processo produtivo da indústria eletroeletrônica e a qualificação dos trabalhadores no Polo Industrial de Manaus. Perspectiva, Florianópolis, v. 24, p. 665-686, jul./dez. 2006.

OLIVEIRA, S. S. B. A "periferia" do capital: na cadeia produtiva de eletroeletrônicos. Manaus: Editora da Universidade Federal do Amazonas, 2007.

PEREIRA, L. L. (Des)emprego no polo industrial de Manaus - setor eletroeletrônico: o trabalhador e a qualificação frente às exigências do capital. 2013. Dissertação (Mestrado em Sociologia) - Universidade Federal do Amazonas, Manaus, 2013.

REIS FILHO, M. M. dos. A saga dos operários em Manaus - 1980. Manaus: Editora da Universidade Federal do Amazonas, 2013. 
SALAZAR, J. P. O novo proletariado industrial de Manaus e as transformações sociais possíveis (estudo de um grupo de operários). 1992. Tese (Doutorado em Sociologia) - Universidade Estadual de São Paulo, São Paulo, 1992.

SAMPAIO, M. da S. Qualificação profissional e empregabilidade no polo de duas rodas da ZFM. 2012. Dissertação (Mestrado em Sociologia) - Universidade Federal do Amazonas, Manaus, 2012.

SCHERER, E. Baixas nas carteiras: desemprego e trabalho precário na Zona Franca de Manaus. Manaus: EDUA, 2005.

SERÁFICO, M. Globalização e empresariado: estudo sobre a Zona Franca de Manaus. São Paulo: Annablume, 2011.

SILVA, M. P. M. Expressões do mundo do trabalho contemporâneo: um olhar para os trabalhadores do Parque Industrial de Manaus. Manaus: Editora da Universidade Federal do Amazonas, 2010.

SMITH, C.; ZHENG, Y. The management of labour in chinese MNCs operating outside of China: a critical review. In: LIU, M.; SMITH, C. (Eds.). China at work: a labour perspective on the transformation of work and employment in China. UK, London: Palgrave Macmillian Education, 2016. p. 361-387.

SPINDEL, C. R. Formação de um novo proletariado: as operárias do Distrito Industrial de Manaus. Revista Brasileira de Estudos da População, São Paulo, v. 4, n. 2, p. 1-38, jul./dez. 1987.

SUFRAMA. SUPERINTENDÊNCIA DA ZONA FRANCA DE MANAUS. Perfil das Empresas com Projetos Aprovados pela SUFRAMA. Manaus: SUFRAMA, 2017. (Relatório de janeiro).

VALLE, M. I. de M. Globalização e reestruturação produtiva: um estudo sobre a produção offshore em Manaus. Manaus: Editora da Universidade Federal do Amazonas, 2007.

VAN LIEMT, G. Hon Hai/Foxconn: which way forward? In: DRAHOKOUPIL, J.; ANDRIJASEVIC. R.; SACCHETTOO, D. (Eds.). Flexible workforces and low profit margins: electronics assembly between Europe and China. Brussels: European Trade Union Institute (ETUI), 2016. p. 45-66.

Texto submetido à Revista em 26.02.2018 Aceito para publicação em 15.01.2019 